\title{
Comparative Analysis of Health Institutions on the Attitude and Practice af Midwives Towards Pregnant Women During Child Delivery In Ogbomoso, Oyo State, Nigeria.
}

\author{
Dr. Florence O ADEYEMO \\ Dept. of Nursing, College of Health Sciences, Ladoke Akintola University of Technology, Ogbomoso, Nigeria.
}

\begin{abstract}
The aim of this study was to compare the attitude and practice of midwives in a mission and government health institutions in Ogbomoso, town in south west Nigeria towards pregnant women during delivery. Five hundred and seventy nine pregnant mothers from antenatal clinic, labour and postpartum ward, were enrolled for this study. Primips were excluded from the study. Four hypotheses were tested.

The study showed that the attitude and practice of mid-wives have great influence on the pregnant women perception about them. There is a mutual relationship between the mid-wife and the pregnant women and this may result to successful child(ren) delivery. The study also revealed that the attitude of mid-wives from Mission hospital is significantly different from the attitude of mid-wives from general hospital. Similarly, the Value for practice of mid-wives from Mission hospital is significantly higher than that of the mid-wives from general hospital. Lastly, the perception of pregnant women toward choice of health institutions shows great significant difference.

The present study suggests the need for strict supervision of midwives to ensure quality care and positive attitude towards women in labour and Stakeholders including Nursing and Midwifery Council should intensify action on continuous education on human relations.
\end{abstract}

Keywords: Attitude, Child Delivery, Health Institutions, Midwives, Practice, Pregnant Women.

STATEMENT OF PROBLEM.

I. Introduction

Women need to be encouraged during delivery. It is believed that with the introduction of modern techniques of practice and the introduction of servicom by the federal government, the midwives' attitude and practice will be better hence, this study.

SIGNIFICANCE OF STUDY.

There are many studies on the attitude, practice and knowledge of midwives towards pregnant women during delivery, but none has given information to show if the midwives current attitude and practice is still the same or there is a better progress modification.

\section{Introduction}

Child birth is a normal phenomenon among human beings but most stressful experience in women. Child delivery is usually accompanied by labour pain which mothers experienced irrespective of their educational, ethnic, social or financial background. This pain is associated with the physiological termination of pregnancy at term to bring about motherhood. This pain is also referred to as labour pain due to its severity and the vigorous task the mother must perform to accomplish result. Response to pain by women will depend on cultural background, individual and physical state [1]. During this period, pregnant women exhibit lots of anxiety. These women need care and support of the health professionals during labour. The health professionals such as doctors and midwives play an important role in the care of pregnant mothers during prenatal, antenatal, delivery and post natal period.

The midwives seem to be closest health professional to pregnant mothers. A midwife is a person who went through the school of midwifery for a period of three years or eighteen months and certified by the Nursing and Midwifery Council of Nigeria. Wikipedia [2] defined Midwifery as a health care profession in which providers offer care to childbearing women during pregnancy, labour and birth, and during the postpartum period. They also help care for the newborn and assist the mother with breastfeeding. Midwives work with women and their families in many different settings. Midwives generally support and encourage natural childbirth in all practice settings. The midwife must be able to give the necessary supervision, care and advice to women during pregnancy, labour and the post-partum period, to conduct deliveries on her own responsibility, and to care for the newborn and the infant [3]. Nurses including midwives are at the forefront of caring for all patients and inadequate care will not only affect the patient, but it has the capacity to adversely affect the nursing profession [4]. Midwives are expected to display a positive caring attitude towards pregnant women 
during delivery and also use their knowledge on pain management to reduce or relief pain. Mahlako [5] believed that the midwives attitude can be influenced by culture, religion, personal experience and professional background. It is also believed that midwives have the ability to relief anxiety because some of these mothers threshold to pain is very low. The relationship between the women in labour and the midwife is important as the midwife ensures that the birth experience is fulfilling and gratifying [6]. Women in labour tend to overestimate their ability to cope with pain, therefore midwives are expected to be courteous, patient and attend to client's need immediately in the practice of safe delivery [7].

Many women lose their lives in the process of childbirth every year. About half a million of women die in sub Saharan Africa from pregnancy related causes and maternal mortality rate (MMR) is between 166 to 1.549 per 100,000 live birth[8]. Nwosu, Odubanjo and Osinusi [9] explained that 'an estimated 500,000 women die each year throughout the world from complications of pregnancy and childbirth and about 55,000 of these deaths occur in Nigeria. Factors that contribute to the high maternal mortality rates in Nigeria include lack of antenatal care, a low proportion of women attended to by skilled birth attendants, and delays in the treatment of complications of pregnancy. Poor utilization of quality health services contribute to maternal mortality rate which may be attributed to the attitude and practice of the skilled workers especially the nurses and midwives. Statistics from different sources have revealed that children and women are the most vulnerable to the threats of poverty and untimely death and a recent World Health Organisation report stated that, more than 600,000 women have died in recent time due to childbirth or pregnancy-related complications while Nigeria accounts for close to 10 per cent of this figure [10]. The death of a woman during pregnancy, labor or pueperium is a tragedy and it carries a huge burden of grief, pain, and is a major public health problem in developing countries because women have an enormous impact on their families' welfare [11]. Potani[12] stated that Callister Mutherica, the first lady of Malawi was persuading the pregnant women to deliver in public health facilities at a National Nurses and Midwives Advocacy Campaign meeting in Lilongwe. She also pleaded with nurses and midwives in Malawi to practice professionally, ethically and with empathy towards pregnant women. It is believed that some nurses are scarring the pregnant women by their attitude and practice. Only one third of births in Nigeria are attended to by doctors, nurses and midwives and the relationship between the health workers and pregnant women during delivery can reduce maternal deaths including related complications but the attitude of many nurses and midwives to women during labour is poor[13]. In contrast, findings on 'Evaluation of satisfaction with midwifery care' revealed that women in the midwife group reported significantly greater satisfaction and a more positive attitude toward their childbirth experience than women in the doctor group $(\mathrm{p}<0.001)$ in Arbour Birth Center, Calgary, Alberta, Canada[14].

Lanre-Abass [15] examines poverty as a major cause of maternal deaths in Nigeria along with the practice of medicine in Nigeria which is different from that of modern medicine because of the uncaring attitude of many health care providers in the context of maternal care. He suggested that in order to reduce maternal deaths in Nigeria, there is need for ethical orientation emphasizing the need to show care to vulnerable patients (for example, pregnant women) irrespective of their socio-economic status. This will enhance quality care and foster good relationships between health-care providers and their patients. At the safe motherhood Initiative conference 1987 in Kenya, participating countries agreed to decrease MMR by $50 \%$ yet this remains high in Nigeria.

The attitude and practice in each hospital defers thus contributing to different experiences of pregnant mothers in developing countries. Some of the experiences the women in Bayelsa state in Nigeria shared were positive, others described serious abuse and neglect by midwives, they were rude, refused to offer assistance, and in some cases threatened women in labour.[16] This attitude may influence pregnant women in labour on the decisions about where to give birth in Ghana [17], thus this study will study is comparing the attitude and practice of midwives in two health institutions in Ogbomoso. \{Mission and State hospitals\}The result of this study will reveal the current attitude and practice of midwives and further assist the health care facilities to plan new strategies on how to improve services rendered not only by midwives but all health workers.

\subsection{MATERIALS AND METHODS}

\section{Methodology}

\subsubsection{Study Design: Descriptive survey}

\subsubsection{Research Settings: Mission Hospital and government hospital in Ogbomoso}

The Mission hospital is a 182 bedded hospital founded 1907. The total numbers of nurses working in this hospital are ninety seven. It has facilities such as medical, surgical, paediatric and maternity wards, eye clinic, dental clinic, intensive care unit, outpatient department, theatre, accident and emergency unit etc. Laboratory services such as X-ray, ultra-sonography, medical microbiology laboratories etc. are also available. IT serves Ogbomoso, Oyo, Igbetti, Iwo and its environment.

Goverment hospital is a 60 bedded hospital founded in 1957 by the then Premier of Western region. The number of nurses working in this hospital is fifty five. It has facilities such as medical, surgical, paediatric 
and maternity wards, theatre, ophthalmic, dental, outpatient department physiotherapy dept., Laboratory services such as X-ray, medical microbiology lab, etc. It serves Ogbomoso, and its environment.

Target Population under Study: Pregnant Clients attending antenatal clinic admitted to labour and postpartum ward.

Sampling Technique: A simple random sampling technique was used to select 579 from both health institutions Instrument: The instrument for collecting the data required for this study is a standardised instrument - Caring Behaviour Inventory (CBI). The content of the questionnaire are divided into four sections namely: demographic data, attitude, practice and perception. Twenty statement items was used to measure attitude, eleven to measure practice and seven to measure perception. For each statement, respondents are asked to state their experience on the attitude and practice and perception of midwives using a four point Likert scale rating, ranging from 1 strongly disagreed to 4 strongly agree.

Validity test: The questionnaire was given to experts for review.

Reliability of the research instrument was done through test-retest method which gave 0.84 reliability coefficient Procedure for data collection: On the receipt of approval from the hospital ethical committees of Mission Hospital and government hospital in Ogbomoso, a descriptive survey questionnaire were be distributed to all interested participants. A consent form and a cover letter were attached to each questionnaire. The questionnaire was first prepared in English and also translated into the Yoruba language. Participants who gave their consents to participate in the study received elaborated explanation on the purpose of the study and the type of questions and how to answer by trained facilitators. Furthermore, to enhance honest and frank responses privacy ensured. Participants were being instructed to complete the questionnaire through the help of the research assistances. The study was conducted within a period of six months.

The returned questionnaire was coded and a statistical package for social sciences (SPSS) was used to analyse the coded response.

The data collected were analyzed using independent $\mathrm{t}$ - test and Regression co-efficient.

Ethical Considerations: The right of the subjects' privacy will be maintained. This includes the issues on restriction and anonymity, also confidentiality.

\section{Results}

Table 1

Regression coefficient of relative contribution of influence attitude and practice of midwives towards pregnant women during delivery

\begin{tabular}{|l|l|l|l|l|l|}
\hline \multirow{2}{*}{ Model } & \multicolumn{2}{|l|}{ Unstandardized coefficient } & $\begin{array}{l}\text { Standardized coefficient } \\
\text { Beta }\end{array}$ & T & Sig \\
\cline { 2 - 4 } & B & Std. Error & & .234 & 3.588 \\
\hline Constant & .559 & .156 & .099 & .000 \\
\hline Attitude of midwives & .026 & .005 & & 2.086 & .000 \\
\hline Practice of mid-wives & .015 & .007 & .038 \\
\hline
\end{tabular}

Table 1 reveals the relative contribution of two predictor variables (attitude of mid-wives and practice of midwives) toward pregnant women in south west Nigeria as it is given by beta weight. The $\beta$ value indicates the contribution of each of the two predictor variables to the criterion variable (perception of pregnant women toward mid-wives). The higher the $\beta$ value, the greater the contribution of the predictor variable. This implies that attitude of mid-wives and practices of mid-wives when used alone are important factors to predict pregnant women perception towards mid-wives. This means that the attitude and practice of mid-wives goes along way to influence pregnant women perception about them and promote mutual relationship between the mid-wife and the pregnant women and this may result to successful child(ren) delivery.

Hypothesis two

Health institutions do not significantly influence attitude of midwives towards pregnant women during delivery. Independent $t$-test was used to test this hypothesis at 0.05 level of significance 
Table 2

Result of Independent $t$-test of difference of Health institutions and influence of attitude of midwives towards pregnant women during delivery

\begin{tabular}{ccccc}
\hline Variable & N & M & SD & t-value \\
\hline Attitude of midwives: Government. Hosp. & 212 & 26.08 & 4.40 & \\
& & & & 7.200 \\
Mission Hosp. & 367 & 28.68 & 4.07 & \\
\hline
\end{tabular}

\section{Significant at 0.05 level, critical $\mathrm{t}=1.96, \mathrm{df}=577$}

The result presented in table 2 shows a mean value of 26.08 for attitude of mid-wives in government hospital and a mean of 28.689 attitude of mid-wives mission hospital. The two groups yielded a $t-$ value of 57.200 which is higher than the critical t-value of 1.96 at 0.05 level of significance with 577 degree of freedom. With this result, the null hypothesis which states that, Health institutions does not significantly influence attitude of midwives towards pregnant women during delivery is rejected.

This implies that there is significant difference in attitude of mid-wives from the different health institution. The mean value indicate that the attitude of mid-wives from Mission teaching hospital (M 28.689) is significantly higher than the value for attitude of mid-wives from government hospital (M 26.080).

Hypothesis three

Health institutions do not significantly influence practice of midwives towards pregnant women during delivery. Independent t-test was used to test this hypothesis at 0.05 level of significance.

Table 3

Result of Independent $t$-test of difference of Health institutions and practice of midwives towards pregnant women during delivery

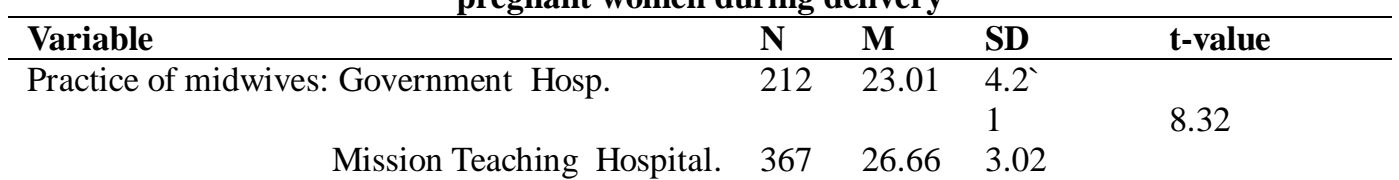

\section{Significant at 0.05 level, critical $\mathbf{t}=\mathbf{1 . 9 6}, \mathrm{df}=577$}

The result presented in table 7 shows a mean value of 26.66 for practice of mid-wives in Govrnment Hospital and a mean of 23.01 for practice of mid-wives in Mission hospital. The two groups yielded a $t$-value of 8.32 which is higher than the critical t-value of 1.96 at 0.05 level of significance with 577 degree of freedom. With this result, the null hypothesis which states that, Health institutions does not significantly influence practice of midwives towards pregnant women during delivery is rejected.

This implies that there is significant difference of practice of mid-wives from different health institution. The mean value indicate that the practice of mid-wives from Mission teaching hospital (M 26.66) is significantly higher than the value for practice of mid-wives from general hospital (M 23.01)

Hypothesis four

Health institutions do not significantly influence perception of pregnant women delivery. Independent t-test was used to test this hypothesis at 0.05 level of significance.

Table 4

Result of Independent $t$-test of difference of Health institutions and perception of pregnant women

\begin{tabular}{llllc}
\hline Variable & N & M & SD & t-value \\
\hline Perception of pregnant women: Govt. Hosp. & 212 & 23.05 & 3.48 & \multirow{2}{*}{ Mission Hosp. } \\
$\quad$ & 367 & 24.53 & 2.77 & \\
& & & & \\
\hline
\end{tabular}

\section{Significant at 0.05 level, critical $t=1.96, d f=577$}

The result presented in table 6 shows a mean value of 23.05 for perception of pregnant women in General Hospital and a mean of 24.53 perceptions of pregnant women in Mission hospital. The two groups yielded a $\mathrm{t}-$ value of 5.616 which is greater than the critical t-value of 1.96 at 0.05 level of significance with 577 degree of freedom. With this result, the null hypothesis which states that, Health institutions do not significantly influence perception of pregnant women during delivery is rejected.

This implies that there is significant difference in perception of pregnant women toward choice of health institutions. The mean value indicate that the perception of pregnant women who attain Mission hospital (M 24.53) is significantly higher than the value for perception of pregnant women who are attended to in general hospital (M 23.05). 


\section{Discussion}

The present study is on the attitude and practice of mid-wives towards pregnant women perception in labour in mission and government hospitals in Ogbomoso, Oyo state, Nigeria. The study revealed that There is a mutual relationship between the mid-wives and the pregnant women and this may result to successful child(ren) delivery as Bluff and Holloway [6] explained that the provision of a client centered service is important where women can express their opinion. WHO/UNICEF(1996)[18] explained that the presence of skilled attendant during child birth can lead to reduced maternal morbidity and mortality rate which is one of the indicators to assess millennium development goal of improving maternal health. Centre for maternal and children enquires (CEMACH) on $27^{\text {th }}$ May 2005 mentioned that poor quality care provided by health workers contributed to the increase in maternal mortality and morbidity rates in Nigeria. Brink [19] asserted that quality care is a major public health concern and it has the potentials of improving the health of the mother and child.

The attitudes of mid-wives from the mission and government hospitals are significantly different in this study. The attitude of mid-wives from Mission hospital (M 28.689) during labour is significantly higher than the value for attitude of mid-wives from government hospital (M 26.080). This implies that the midwives in Mission hospital show better positive caring attitude towards their clients than the midwives in government hospital. It therefore explained the reason why mission hospital receive better patronage from pregnant mothers because Mitchell [4] stated that inadequate care will not only affect the patient utilization of hospital facilities, but it has the capacity to adversely affect the nursing profession, thus supporting Omoruyi(2008) report that the relationship between the health workers and pregnant women during delivery can reduce maternal deaths including related complications

Similarly, this study showed that there is a significant difference in the practice of mid-wives from both Mission and government health institutions because the mean value indicate that the practice of mid-wives from mission hospital (M 26.66) is significantly higher than the value for practice of mid-wives from government hospital (M 23.01). This may be as a result of discipline instilled on the midwives in mission hospital because all midwives in both hospitals were duly trained. There are policies that are strictly adhered to in the mission hospital.

Lastly, there is significant difference in the perception of pregnant women toward choice of health institutions because the mean value indicate that pregnant women who attended mission hospital (M 24.53) is significantly higher than that of pregnant women who attended government hospital (M 23.05) due to positive caring attitude and adequate skills in the practice of midwifery. Studies in Ghana revealed that the attitude of the health workers towards pregnant women has a major influence on of the choice about where to give birth [17] which is in line with this present study.

\section{Conclusion}

Despite the increasing activities of the nurses and midwives to improve the quality of care, it was observed that mothers still complain of midwives' attitude and practice. It seems the midwives do not take the views of the mothers for effective care. This study revealed that there is a mutual relationship between the midwives and the pregnant women. The attitude and practice of mid-wives from the mission and government hospitals are significantly different.

\section{References}

[1] V.R. Bennett and L.K. Brown, Myles textbook for Midwives (Churchill Living stone, 1999)

[2] Midwifery, Wikipedia. http://www.wikipedia.com/midwifery

[3] Leap Nicky, Midwife Power: A Paper presented at the Future Birth 94th Conf. for Associates in Childbirth Education, Australia, 1994.

[4] S. Harvey, D. Rach, M.C. Stainton, J. Jarrell, R. Brant, Evaluation of satisfaction with midwifery care, PubMed Journal, 18(4), 2002, 260-267.

[5] K.M. Mahlako, The perception of selected groups of Midwives towards women experience in labour, masters diss., University of South Africa, South Africa, 2008.

[6] R. Bluff and I. Holloway, They know best: Women's perceptions of midwifery care during labour and childbirth, PubMed, 10 (3), 1994, 157-164.

[7] L.O. Ogunjimi, Rosemary Thomas, Ibe and M.M. Ikorok, Curbing maternal and child mortality: The Nigerian experience, International Journal of Nursing and Midwifery, 4(3), 2012, 33-39.

[8] C.I. Iyaniwura and Q. Yusuf, Utilization of Antenatal care and delivery services in Shagamu, South Western Nigeria, African Journal of Reproductive Health, 13(3), 2009, 110-123.

[9] Nwosu Joanna, M. Oladoyin Odubanjo and Osinusi O. Bandele, Overview of Maternal and Infant deaths in Nigeria: Reducing Maternal and Infant Mortality in Nigeria, The Nigerian Academy of Science forum on evidence-based health policy making workshop summary, 2009, 1-8.

[10] Bakare Biliqis, Tackling maternal and child mortality in Nigeria: Advocacy for maternal and infant deaths in Nigeria, 2011. Available on: http://www.punchng.com/Articl.aspx? theartic=Art201108030434517

[11] B. Mitchell, Attitudes of nurses towards AIDS Patients. The Australian Electronic Journal of Nursing Education, 4, 1999.

[12] Potani Frazer, Some health workers are scaring pregnant women, Journal on attitude \& practice of midwives to women in labour, 2011. 
[13] G. Omoruyi, Causes of Maternal Mortality in Nigeria, Sunday Observer Bendel Newspaper Company Limited, 2008.

[14] Patricia McNiven, Michael C. Klein, Nazli Baradaran, Jocelyn Tomkinson, J. C. Hearps \& Lee Saxell, Midwives' belief in normal birth: The Canadian survey of maternity care providers' attitude towards labour and Birth, Canadian Journal of Midwifery Research and Practice, 2(10), 2011, 1-11.

[15] Lanre-Abass .A. Bolatito, Poverty and maternal mortality in Nigeria: towards a more viable ethics of modern medical practice, International Journal for Equity in Health, 7(11), 2008, PMC2390565.

[16] Onasoga, A. Olayinka, Opiah, Margaret Mombel and Osaji Teresa Achi, Perceived effects of midwives attitude towards women in labour in Bayelsa State Nigeria, Archives of Applied Science Research, 4 (2), 2012, 960-964.

[17] D'Ambruoso, Lucia Abbey and Mercy, Midwives' attitudes to women in Labour in Ghana, BMC Public Health, 5(140), $2008,1-2$. 